\title{
$\mathrm{MADS}$ 를 기반으로 한 전거데이터 상호운용성에 관한 연구*
}

\section{A Study on the Metadata Authority Description Schema for the Interoperability of Authority Data}

이 혜 원 (Hyewon Lee)**

\section{초 록}

본 연구에서는 현재의 전거제어 현황을 살펴보고 도서관 전거데이터 공유와 활용을 위한 메타데이터 전거기술 스키마(Metadata Authority Description Schema: MADS)를 소개하였다. 또한 에이전트(사람, 조직), 사건, 용어(토픽, 장르, 지리 등)에 관한 전거데이터 XML 스키마인 MADS의 특성과 그 활용방안을 확인하였다. 마지막으로 본 연구에서는 MADS를 기반으로 한 전거데이터 상호운용성을 살펴보고자 하였다.

\section{ABSTRACT}

This study analyzed the current condition of authority control, introduced the MADS(Metadata Authority Description Schema) for authority data. MADS supports encoding an authority description for a agent(person, organization), event, term(topic, temporal entity, genre, geographic entity, hierarchical geographic entity, occupation) and defines main elements, subelements, and attributes using the XML schema language. Lastly, using the MADS's characteristics, this study proposed the effective use plans of interoperability of authority data.

키워드: 전거제어, 인명 전거, 전거데이터, 메타데이터 전거기술 스키마, 메타데이터 자원기술 스키마, 상호운용성 Authority Control, Name Authority, Authority Data, Metadata Authority Description Schema(MADS), Metadata Object Description Schema(MODS), Interoperability

* 이 논문은 2012학년도 서울여자대학교 교내학술특별연구비의 지원을 받았음.

** 서울여자대학교 사회과학대학 문헌정보학과 조교수(hwlee@swu.ac.kr)

논문접수일자 : 2012년 12월 19일 논문심사일자 : 2012년 12월 20일 게재확정일자 : 2012년 12월 23일 


\section{1. 서 론}

전거데이터에 대한 중요성은 도서관 목록과 관 련된 국제회의와 도서관 분야의 국제 기구인 국제 도서관연맹(International Federation of Library Associations and Institutions: IFLA)이 발표 한 문건을 통해서도 잘 나타나 있다. 1961년 프 랑스 파리에서 개최된 국제목록원칙회의(ICCP) 에서 최초로 국제적 합의를 통해 발표된 '국제목 록원칙규범(Statement of International Cataloguing Principles)'은 사실상 목록의 표목과 관련된 원칙이라고 할 수 있다. 1977년 프랑스 파리에서 IFLA와 유네스코가 공동으로 개최한 국가서지에 관한 국제회의 권고문 제 13 조에 따 르면 “... 각 국가서지작성기관은 국제적인 가 이드라인에 따라 국가명, 개인명 및 단체명, 통 일서명에 대하여 전거통제시스템을 유지 · 관리 해야 한다.”고 하였다. 심지어는 "전거데이터를 사용하지 않은 목록은 엄밀히 말해서 목록이 아 니라 하나의 리스트에 불과하다”고 하였다(국 립중앙도서관 2009, 4). 국가 차원의 전거데이 터 관리는 지금까지 강조되고 있으며, 더 나아 가 국제적인 차원에서의 전거데이터 활용과 관 리에 대해 도서관계뿐만 아니라 정보기술 분야 에서도 많은 연구를 진행하고 있다. 20세기 후 반, 네트워크 환경과 데이터베이스 관련 기술의 발전은 국제적인 차원의 전거정보 공유 및 교환 에 많은 도움을 주었으며 국제적으로 전거데이 터 상호운용성을 고려한 전거데이터 활용 스키 마 설계를 지원하였다.

도서관 목록 레코드는 저작을 위한 접근점, 개체에 대한 서지 기술, 도서관 소장 정보를 제 공하는 등 세 가지의 근본적인 기능을 가지고
있다(Burger 1985, 3). 도서관은 이용자의 관점 에서 이러한 근본적인 기능들을 분리할 수 없 기 때문에 도서관 내 - 외부의 정보관리시스템 들을 통합적으로 관리할 필요가 있겠다. 이용 자는 다양한 접근점을 통해 개체에 대한 서지 기술에 접속하며 그러한 접속은 특정 도서관 시 스템에 국한되지 않는다. 이용자에게 의미 있 는 서지 정보 중 하나는 전거데이터이며, 그 전 거데이터는 여러 시스템에서 제공된다. 그러므 로 이용자에게 제공되는 정보시스템은 다양한 시스템에서 전달되는 전거데이터의 의미들을 확인하고 연계할 수 있는 체계로 설계되어야 한다.

도서관 전거데이터 활용을 통해, 도서관은 웹 포털에서 제공되는 콘텐츠와 경쟁할 수준의 정 보를 이용자에게 제공할 수 있는 기회를 얻을 수 있다.

본 논문에서는 현재의 전거제어 현황을 살펴 보고 도서관 전거데이터 공유와 활용을 위한 메 타데이터 전거기술 스키마(Metadata Authority Description Schema: MADS)를 소개하였다. 또 한 도서관의 실제 전거데이터를 활용하여 MADS 를 기반으로 한 전거데이터 상호운용성을 살펴 보았다.

\section{2. 전거제어 동향}

각국의 목록규칙은 기본적으로 특정한 하나의 형식을 전거형식으로 규정하고 이 형식을 목록 전반에 걸쳐 대표형식으로 사용하도록 강제하는 원칙이었다. 그런데 기계가독목록의 출현과 이들 포맷간의 데이터 변화에 대한 축적된 경험에 힘 
입어 서지레코드의 국제적 교환이 가능하게 되 었다. 이에 따라 특정 국가에서 생산된 서지레코 드를 재사용할 수 있게 되었고, 이 서지레코드에 포함된 전거데이터도 함께 사용할 수 있게 된 것 이다. 이런 점에서 서지적 개체를 하나의 표준형 식으로 사용하도록 강제한 종래의 국제서지제어 (Universal Bibliographic Control; UBC) 원칙 이 도전을 받게 되었는데, 그 주된 요인은 모든 서지기관이 하나의 전거파일을 관리할 수 없다 는 점이고, 또 다른 요인은 다른 서지기관에서 관 리되는 전거파일을 특정 서지기관이 이용하기 어 렵다는 점이다(김태수 2004, 3).

즉 이용자의 언어 환경과 정보욕구를 충족시 킬 수 있도록 표목의 전거형식에 대한 차이를 인정할 필요가 있는 것이다. 이에 도서관과 관 련된 다양한 전거제어 스키마나 전거시스템이 등장하였다.

대표적인 전거제어 스키마는 가상의 국제전거 파일(Virtual International Authority: VIAF) 이다. VIAF에서는 동일한 서지적 개체에 대해 각국이 대등한 전거레코드를 유지하는 것으로, 이를 통해 특정 국가나 특정 문화에 기반한 이 용자들의 요구를 반영할 수 있으며, 도서관에서 는 특정 이용자 계층을 위해 상호참조와 전거형 식의 표목간의 연결구조를 확립할 수 있다. 이 에 따라 다른 문자에 의한 이형(異形)을 상호 참조로 기술할 수 있다(김태수 2008, 313-314). $\mathrm{VIAF}$ 시스템은 전거 작업에 소요되는 비용을 국제적으로 분담함으로써 비용을 절감하면서 도 각 국가별 언어나 선호하는 문자 표기를 사 용할 수 있는 잇점이 있다. 더욱이 참여하는 국 가가 미국을 비롯해서 유럽 전역으로 확대되어 나가면서 그 효용성은 점차로 높아지고 있다
(김미향 2009, 33-38).

국외의 대표적인 도서관 전거시스템은 $\mathrm{NACO}$ (Name Authority Cooperative Program of the $\mathrm{PCC}$ )이다. $\mathrm{NACO}$ 는 공동목록프로그램(Program for Cooperative Cataloguig: PCC)의 이름전 거 프로그램이다. 이 프로그램을 통해서 참가기 관은 $\mathrm{NACO}$ 전거파일에 이름이나 경우에 따라 서는 이름/표제, 통일표제, 총서의 전거레코드 를 제공한다. 이 파일은 영어권의 목록업계에서 는 이름표목에 관한 국제적인 사실상의 표준이 되고 있으며, 대략 700 만 건의 전거레코드를 가 지고 있으며 1 년에 25 만 레코드의 증가가 이루 어지고 있다(국립중앙도서관 2009, 78-82).

\section{3. 메타데이터 전거기술 스키마 분석}

디지털 자원을 효과적으로 관리하기 위해 IFLA 와 미국국회도서관이 중심이 되어 여러 기준들 을 제시하고 있다. 특히 MARC 형식과의 호환 을 고려하고 디지털 환경을 수용하는 새로운 기준들이 90 년대부터 꾸준히 연구되었다.

기계를 위한 부호화식 기술 규칙은 인간이 이해할 수 있는 언어로 그 표현이 변화되었으 며, 자유로운 데이터 공유를 위해 하드웨어, 소 프트웨어, 어플리케이션 등과는 독립적으로 운 영될 수 있는 웹 언어인 XML를 수용하였다. 이러한 노력들은 자원의 기술 체계를 제시하는 메타데이터 자원기술 스키마(Metadata Object Description Schema: MODS) 와 디지털 자원의 교환을 위한 메타데이터 부호화 및 전송 표준 (Metadata Encoding \& Transmission Standard: 
METS)이라는 기준들을 발전시켰다.

$\mathrm{MODS}$ 는 기술 메타데이터의 역할을 수행하 여 자원에 대한 설명 즉 콘텐츠의 지적 내용을 표현하는 것이다. MODS는 DC 메타데이터보 다는 더 자세한 요소들을 제시하고 있으며, 다 른 서지정보 교환을 위한 메타데이터와의 호환 성을 고려하였다.

METS는 디지털 도서관 기준이라고 할 수 있으며, 디지털 자원에 관한 메타데이터를 담 기 위한 표준 용기로써, 전통적인 도서관 목록 의 MARC 레코드와 유사한 기능을 지니고 있 다. 그러나 METS는 그 구조 상 디지털 자원을 기술하는데 필요한 내용(콘텐츠)의 형식에 대 해서는 규정하지 않고 있다. 내용의 표준화를 규정하지 않았기 때문에 메타데이터의 교환 및 공유를 위한 METS의 역할은 일정 부분 한계를 지니게 되었다(김태수 2008, 256-257). 그러나 이러한 한계는 XML 이름공간으로 해결될 수
있는데, 서지정보를 제공하는 MODS와 관리, 구 조, 기술(technical) 과 관련된 정보를 제공하는 $\mathrm{METS}$ 를 함께 활용하는 것이다.

콘텐츠의 지적 내용을 제공하는 서지적인 정보 는 전거데이터를 포함하고 있으며, 이는 MARC 형식에서도 그대로 반영되고 있는 것이다. 반면, MARC의 데이터를 수용하는 MODS는 서지적 인 정보에 중점을 두고 있으며, 그와 연결된 전거 데이터에 대한 부분은 요소로 정의되지 않았다. MODS/MADS 편집위원회(MODS Editorial Committee)와 미국국회도서관 기준 개발 센터 인 Network Development and MARC Standards Office에서는 메타데이터 전거기술 스키 마(Metadata Authority Description Schema: $\mathrm{MADS}$ )를 제안하였으며, 지금도 지속적으로 관심으로 가지고 발전시키고 있다.

MODS, MADS, METS 간의 관계 설명은 〈그림 1〉과 같다. 〈그림 1〉은 다음과 같은 관계

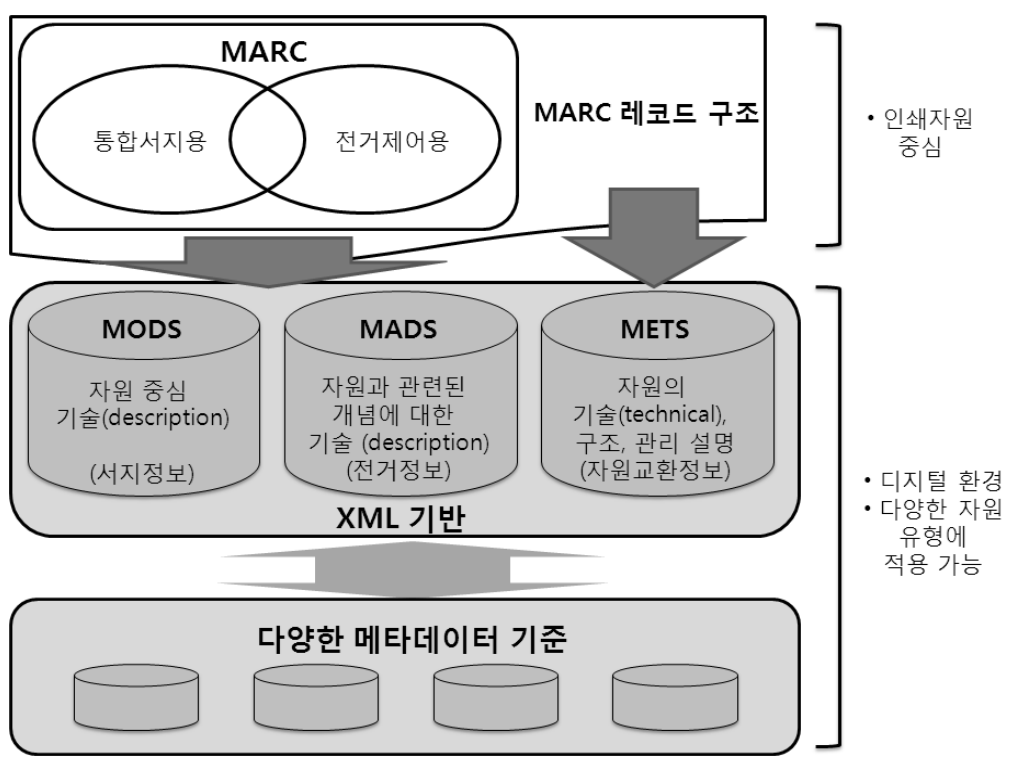

〈그림 1〉MODS, MADS, METS 간의 연계성 및 특성 
를 보여주고 있다. 첫째, MODS와 MADS는 $\mathrm{MARC}$ 형식을 계승한 것이고, 둘째, MODS, MADS, METS 체계는 XML으로 표현되기 때 문에 다른 메타데이터 기준과도 호환이 가능하 며, 독립적으로도 활용가능하다. 셋째, MODS, MADS, METS 체계는 디지털 환경을 고려하고 다양한 자원 유형을 수용할 수 있는 기준이다.

본 연구에서 다루고자 하는 MADS는 에이전 트(사람, 조직), 사건, 용어(토픽, 장르, 지리 등) 에 관한 전거데이터 XML 스키마이다(MADS 2011). 본 연구에서는 다음에 제시된 MADS의 설계 원칙, 레코드 구조, 사례 등을 살펴봄으 로써, MADS의 특성과 그 활용방안을 확인하 였다.

\subsection{MADS 설계 원칙}

MODS 편집 위원회에서는 2009년 9월 MODS 와 MADS의 발전 방안에 대한 설계 원칙을 제 안하였다. MODS는 자원 기술 부호화를 위한 $\mathrm{XML}$ 스키마이자 가이드라인이다. 또한 MODS 는 자원의 검색, 관리 및 접근을 지원하는 동시에 부호화된 기술을 교환하고 관리하는 것이다. 그 리고 MADS는 전거 기술 부호화를 위한 XML 스키마이자 가이드라인이다. 또한 MADS는 자 원 기술에 사용된 데이터 통제, 표준화 및 관리 를 지원하는 동시에 부호화된 기술을 교환하고 관리하는 것이다(MODS 2009).

MODS와 MADS는 독립적으로 사용가능하 지만, MODS 레코드와 MADS 레코드를 연결 하여 사용할 수도 있다.

MODS 편집 위원회에서는 MODS와 MADS 발전에 적용될 수 있는 공동의 설계 원칙들을
다음과 같이 정의하였다(MODS 2009).

- 지역화와 이용자 요구를 지원해야 한다. 이를 위해서는 MODS와 MADS 스키마에 속하지 않 은 요소들을 'extension'으로 선언할 수 있어야 하며, 속성 값을 제한하지 않고 적용되는 범위에 따라 요소들을 정의할 수 있어야 한다. 또한 다른 스키마에서 사용되는 요소들을 포함할 수 있는 기회를 제공해야 한다.

- 기술하고자 하는 실제에 대한 폭넓은 수용이 필요 하다. 이를 위해서는 첫째, 채택된 기준(예. AACR2) 과 이를 자원에 적용할 기술 방법 등에 대한 정보 즉 요소와 속성을 다양하게 제공해야 하며, 둘째, 자연 언어에 대한 정보를 통제하여 이용자가 선 택할 수 있는 기회를 제공해야 한다. 마지막으로 는 기술 작성에 대한 수준-간략 또는 완전- 등을 제공해야 한다.

- 훈련, 활용 및 실행에 소요되는 비용을 줄일 수 있도록 상대적으로 적은 요소와 속성을 유지해야 한다. 이를 위해서는 첫째, 요소 수준보다 아래인 메타 정보 표현을 위해 'authority', 'source, 'type' 등과 같은 요소들이 필요하며, 둘째, 상당수 이용 자의 요구 - 검색, 표현, 연결, 커뮤니케이션 등 - 에 의해 새로운 요소나 속성을 정의할 수 있어야 한다. 마지막으로 하나의 요소나 속성은 같은 의 미로 적용될 수 있는 상황에서는 재사용될 수 있어야 한다. 예를 들면, 'name'나 'title'은 'subject' 요소 안에서도 재사용될 수 있다.

- 자원 및 전거 기술이 상호 활용될 수 있도록 지원 해야 한다. 이를 위해서는 첫째, 데이터 부호화 형식에 대한 폭넓은 수용이 필요하며, 특히 최근 에 가장 많이 사용되는 XML에 대한 호환이 중요 하다. 둘째, MODS와 MADS가 어떻게 적용되 었는지에 대한 상세한 기록이 제공되어야 한다.

- 부호화에 대한 유효성을 보장해야 한다. 이를 위해서는 XML 스키마와 같은 유효성이 보장되 는 툴을 사용해야 하며, 'version' 속성을 활용하 
여 XML 스키마의 버전을 확실하게 전달해야 한다.

- XML 스키마에서 요소를 표현하고 정의하는 것 으로 MODS와 MADS 요소들이 다른 기준과 어플리케이션에 사용될 수 있는 기반을 제공해야 한다.

- 변환이 고려되는 시점에서는 이전 버전과 호환 될 수 있는 옵션들을 통해 구조와 콘텐트의 지속 성을 유지해야 한다.

- 특정 정보를 부호화할 때는 하나의 요소와 속성 만을 이용하여 정의하고 이에 대한 일관성을 유 지해야 한다.

- 기술데이터의 색인을 제공해야 한다. 이를 위해 서는 첫째, 주제, 표제, 이름 등과 같은 검색에 자주 쓰이는 정보들을 위해 특정한 요소와 속성 들 정의해야 하며, 둘째, 색인을 활용할 수 있는 구조화된 스키마를 활용해야 할 것이다

- 기술데이터 표현에 대한 설명을 제공해야 한다. 이를 위해서는 주제, 표제, 이름, 주기 등과 같은 표현에 자주 쓰이는 정보의 특정한 요소와 속성 을 정의해야 한다. 기술 표현에 대한 통제를 위해 'name/displayForm'과 같은 요소와 'displayLabel' 등과 같은 속성 등을 정의할 수 있을 것이다.

- 쉽게 이해할 수 있는 요소와 속성 이름을 작성해 야 한다.

- 'extension' 요소 등을 활용하여 요소 셋의 확장 가능성을 보장해야 한다.

- 메타데이터와 레코드 자체에 대한 정보를 제공 해야 한다. 'recordInfo'와 그 세부요소들은 메타 데이터, 목록 언어, 목록 규칙 등을 제공하는 정보 를 부호화하는 수단으로 쓰이게 된다.

- 자원 및 전거 기술을 부호화하는 DC, MARC, VRA Core 등과의 호환 가능성이 보장되어야 한다. 이를 위해서는 다른 기술 체계와 매핑될 수 있도록 충분한 요소와 속성에 대한 설명을 제공해야 한다.

- 'authority' 속성을 통해 정의된 자원 및 전거
기술에 대한 통제 어휘를 제공해야 한다.

위에서 제시한 설계 원칙들은 MODS와 MADS 에 동시에 적용할 수 있는 항목들이며, 이러한 항목들은 MADS의 기능을 이해하고 더 나아가 $\mathrm{MADS}$ 의 활용 방안을 제시할 때 중요한 근거 요 소로 활용될 수 있겠다.

$\mathrm{MODS}$ 편집 위원회에서는 자원 간의 전체부분이나 유사 관계에 대한 기술을 제공하는 것, 모든 형태의 자원 기술을 부호화하는 것, 에이 전트와 자원의 관계를 부호화 하는 것 등의 세 가지 설계 원칙은 $\mathrm{MODS}$ 만이 갖는 고유한 것 이라고 제시하였고 반면, 이름, 표제, 토픽, 시 간, 장르, 지명, 지명의 계층적인 표현, 직업 등 에 대한 전거 기술을 부호화하는 것은 MADS 에서 적용될 수 있는 설계 원칙이라고 강조하였 다(MODS 2009).

\subsection{MADS 레코드 구조}

본 장에서 설명되는 MADS 레코드 구조는 2012년 4월에 업데이트된 MADS 2.0 버전을 기반으로 설명하고자 하였다.

MADS 요소는 기본 요소(root elements), 핵 심 요소(main elements), 기술 요소(descriptor elements), 기타 요소(minor elements) 등으 로 구성된다. 기본 요소는 〈madsCollection〉과 〈mads〉 등이 있다. MADS 레코드들의 그룹은 MADS 컬렉션 요소인 〈madsCollection〉에 포 함되며, 개별 MADS 레코드는 〈mads〉 아래에 서 생성된다(MADS 2012b).

〈mads〉 아래 생성되는 요소는 핵심 요소와 기 타 요소이다. 핵심 요소는 전거 〈authority〉, 연관 
〈related〉, 이형 〈variant〉 요소 등으로 구성된다. 〈authority〉 요소는 필수 요소이며, 하나 이상의 하위 요소를 가지고 있어야 한다. 하위 요소는 기 술 요소(〈name〉, 〈titleInfo〉, 〈topic〉, 〈temporal〉, $\langle$ genre〉, 〈geographic〉, 〈hierarchicalGeographic〉, 〈occupation〉) 가 되며, 기술 요소는 〈authority〉 뿐만 아니라 〈related〉, 〈variant〉 요소 등 모든 핵심 요소의 하위 요소가 된다. 기타요소는 전 거개체를 식별하기 위한 정보로, 현 목록 환경 및 웹 자원과의 연계 측면에서 의미 있는 정보 이다. 특히 자관의 동명이인 식별을 도와주는 정보로도 유용하게 사용될 수 있겠다.

전체적인 MADS 레코드의 요소 구조는 다 음 〈그림 2 〉와 같다.

〈그림 2〉를 중심으로 한 핵심 요소들에 대한
설명은 다음과 같다. 전거 〈authority〉 요소는 에이전트(개인이나 조직), 사건, 표제, 용어(토 픽, 장르 지리)의 표준화된 전거 형식을 담는 컨 테이너(용기)이며, 다른 언어나 스크립트로 된 전거 형식들만 중복이 가능하다. 연관 〈related〉 요소는 전거 형식과 관련 있는 이름이나 용어 를 포함하며 도서관 목록의 도보라 참조(see also) 에 해당하는 것이다. 〈related〉 요소의 타 입 속성으로는 earlier(이전 이름의 형식), later (뒤에 변경된 이름의 형식), parentOrg(모기 관명), broader(주제전거에서의 상위 표목), narrower(주제전거에서의 하위 표목), equivalent (다른 목록이나 시소러스에서 쓰이는 동등한 표 목), other(기타) 등으로 나뉜다. 이형 〈variant〉 요소는 전거 형식을 고려하지 않은 이름이나 용

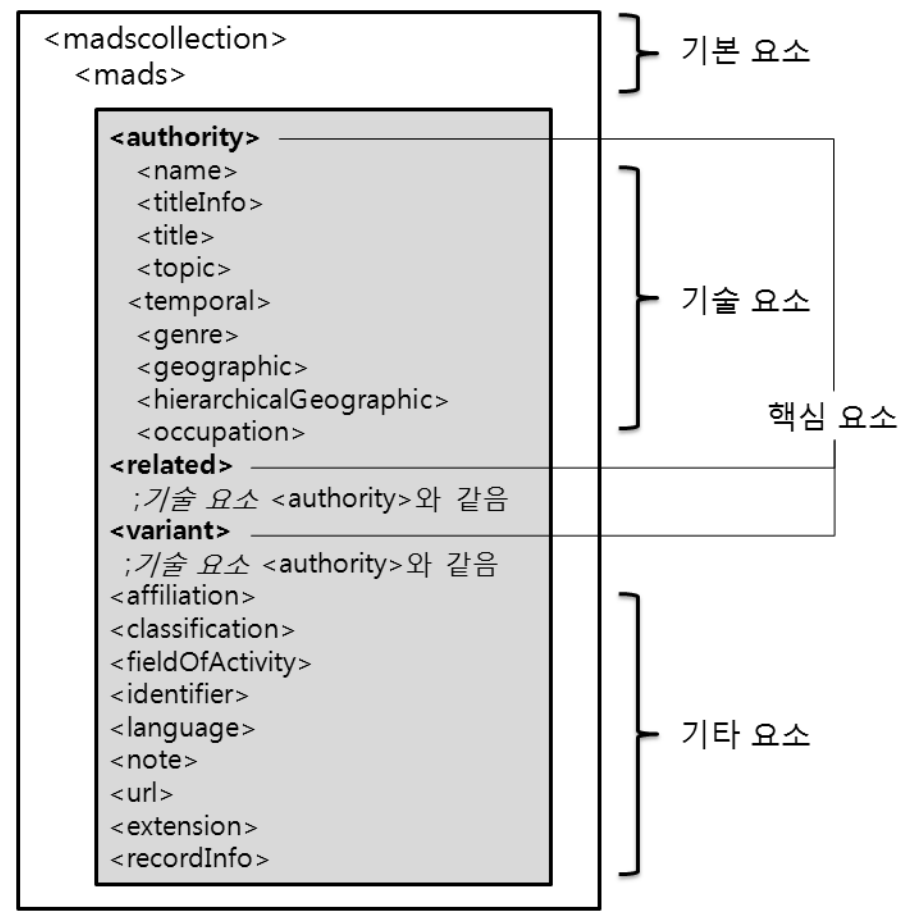

〈그림 2〉MADS 레코드의 요소 구조 
어를 포함하는 것으로 $\mathrm{MARC}$ 전거 필드 $4 \mathrm{XX}$ 에 해당한다. 〈variant〉 요소의 타입 속성은 다 음과 같다(MODS 2011).

- $\operatorname{acronym}($ 두문자어) : 〈authority〉의 이름에 대 한 이명으로 대부분은 기관명에 적용됨.

- abbreviation(약어) : 표제에 적용되는 것으로 색 인 작성 및 식별을 목적으로 함.

- translation(번역): 이름이나 표제를 번역한 이형.

- expansion(확장) : 〈authority〉의 이름을 확장 한 형식.

- other(기타): 특정한 이형 형태를 가지지 않은 것.

- otherType(기타타입) : 스키마 안에서 열거되지 는 않지만 특정한 이형 형태를 가지고 있는 것.

- hidden(숨겨진) : 디스플레이하지 않은 이형.

MADS는 MARC21의 형식을 계승하는 것으 로 표목이라는 개념을 포함하고 있다. 즉 MADS 는 전거데이터로 사용되는 개체에게 하나의 대 표형식을 부여하며, 표목에서 사용하는 대표형 식, 도보라 참조 보라 참조 등과 같은 개념을 사
용하고 있다.

$\mathrm{MADS}$ 기술 요소는 다음 〈표 1)과 같다(MADS 2012b).

MADS 기타(minor) 요소는〈affiliation〉, $\langle$ classification〉, 〈fieldOfActivity〉, 〈identifier〉,

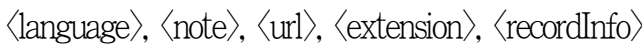
등이며, 자세한 설명은 다음과 같다(MADS 2012b).

-〈affiliation〉: 개인, 조직 연락 정보를 제공하는 것으로, 지위〈position〉, 기관명 〈organization〉, 주소〈address〉, 전화번호〈phone〉, 팩스번호 $\langle\mathrm{fax}\rangle$, 이메일주소〈email〉, 시간 및 유효 일자 〈hours〉, 〈dateValid〉 등의 서브 요소들을 포함.

-〈classification〉: 적용된 분류 체계나 청구기호 와의 연결.

-〈fieldOfActivity〉: 개인 및 기관의 전문성 및 능숙함이 표현되는 분야.

-〈identifier〉: 레코드 안에서 개체에 부여되는 고유 식별자.

-〈language〉: 컨테이너 요소 중의 하나이며, 〈languageTerm〉 하위 요소에 개체와 관련된

〈표 1〉MADS 기술(descriptor) 요소

\begin{tabular}{|c|c|c|}
\hline 요소명 & 설명 & KORMARC 전거 필드와 연계 \\
\hline$\langle$ name $\rangle$ & - 개인, 단체, 사건, 회의, 가족에 활용 & $\mathrm{X} 00, \mathrm{X} 10, \mathrm{X} 11$ \\
\hline$\langle$ titleInfo $\rangle$ & • 표제 정보 & X00 \$t, X10 \$t, X11 \$t, X30 \\
\hline$\langle$ topic〉 & $\begin{array}{l}\text { - 주제 전거 } \\
\text { • 다양한 시소러스 활용 } \\
\text { - 토픽을 나타내는 주제 }\end{array}$ & $\mathrm{X} 50, \mathrm{X} 80$ \\
\hline$\langle$ temporal〉 & $\begin{array}{l}\text { - 주제 전거 } \\
\text { - 다양한 시소러스 활용 } \\
\text { - 시간/연대순을 나타내는 주제 }\end{array}$ & X82 \\
\hline 〈genre〉 & $\begin{array}{l}\text { - 장르 표목: 장르를 표현하는 용어를 포함 } \\
\text { - 다양한 시소러스 활용 }\end{array}$ & 완전하게 일치되지는 않지만 $678 \$ a$ 사용 \\
\hline$\langle$ geographic〉 & • 지리를 나타내는 개체의 전거 & X51, X81 \\
\hline$\langle$ hierarchicalGeographic〉 & - 계층적으로 표현된 지명의 전거 형식 & $\begin{array}{l}\text { 계층적인 표현을 정확하게 제시하지는 않지만 } \\
\text { X } 51, \text { X81 필드 사용 }\end{array}$ \\
\hline$\langle$ occupation〉 & - 직업에 대한 전거 형식을 제공 & 완전하게 일치되지는 않지만 $678 \$ a$ 사용 \\
\hline
\end{tabular}


언어 값을 기술하고, 스크립트 언어 값은 〈script Term>에 표현함; 반복 가능.

-〈note〉: 일반적인 정보를 제시하는 것으로 변천 (application history), 서지 및 역사적인 정보를 제공 (biographical/historical), 삭제표목정보(deletion information), 업무용(nonpublic), 정보원 없음 (notFound), 정보원 있음(source), 주제 예시 (subject example) 등이 있음.

- 〈url 〉: 개인 홈페이지나 기관의 웹 사이트 등과 같은 개체와 관련된 URL.

-〈extension〉: 로컬에서 정의할 수 있는 필드처 럼 $\mathrm{MADS}$ 에서 포함되지 않은 정보를 제공.

-〈recordInfo〉: 메타데이터 관리를 위해 필수적 인 입력해야 할 정보들을 포함하는 컨테이너 요소; $\langle$ recordContentSource〉, 〈recordCreationDate〉, $\langle$ recordChangeDate〉, 〈recordIdentifier〉, 〈record Origin〉, 〈languageOfCataloging $\rangle$, 〈description Standard $>$ 등을 포함.

지금까지 살펴본 바에 의하며 MADS 요소들 은 $\mathrm{MARC}$ 보다 더 많은 요소들을 취하고 있고, 이용자의 보다 다양한 정보 요구에도 대처할 수 있는 수준을 제공한다. MADS와 MARC와의
연계를 고려한다면 MARC에서 MADS로의 변 환은 수월하게 진행될 수 있지만 MADS로 정 의된 데이터를 MARC 포맷으로 변환할 때에는 데이터 손실이 일어나게 된다.

\subsection{MADS 구축 사례}

MADS에 실행되는 레지스트리는 MADS 홈 페이지를 통해 접근할 수 있으며, Library and Archives Canada(LAC)의 Canadian Authorities 와 North Carolina State University Library의 E-Metrix 등이 있다.

그중 LAC Canadian Authorities는 이름 표제, 통일표제, 연속간행물 표제를 통제하는 캐나다 전거레코드를 제공하고, 해당 레코드를 MARC21, MARC XML, MADS 등으로 저 장할 수 있는 인터페이스를 가지고 있다.

〈그림 3〉은 미국 대통령 'Obama, Barack'을 $\mathrm{LAC}$ 에서 검색한 화면이고, 〈그림 4〉는 해당 레코드에 대해 다운로드 파일 포맷을 제시한 화면이다.

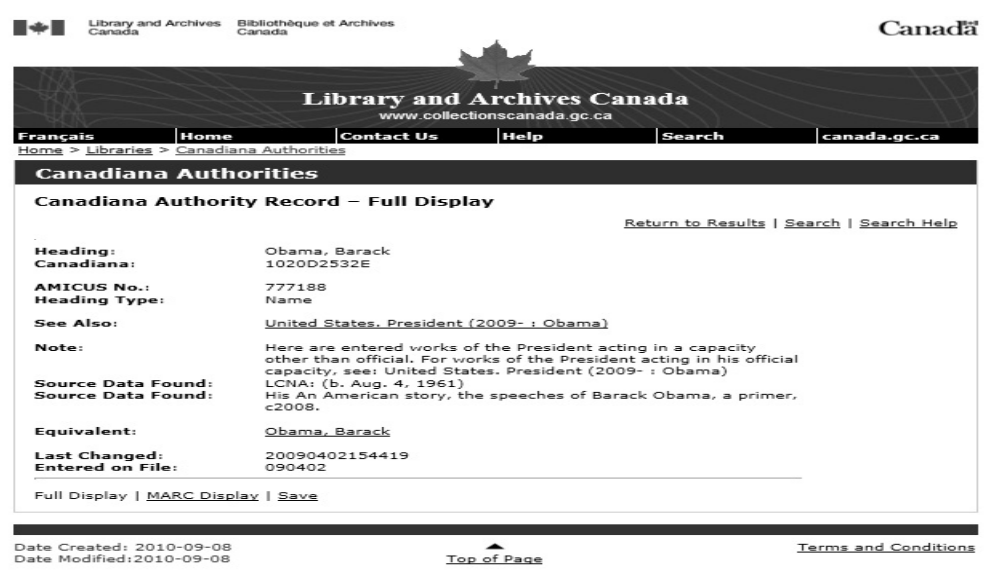

〈그림 3〉LAC 전거레코드 사례 1; Obama, Barack 


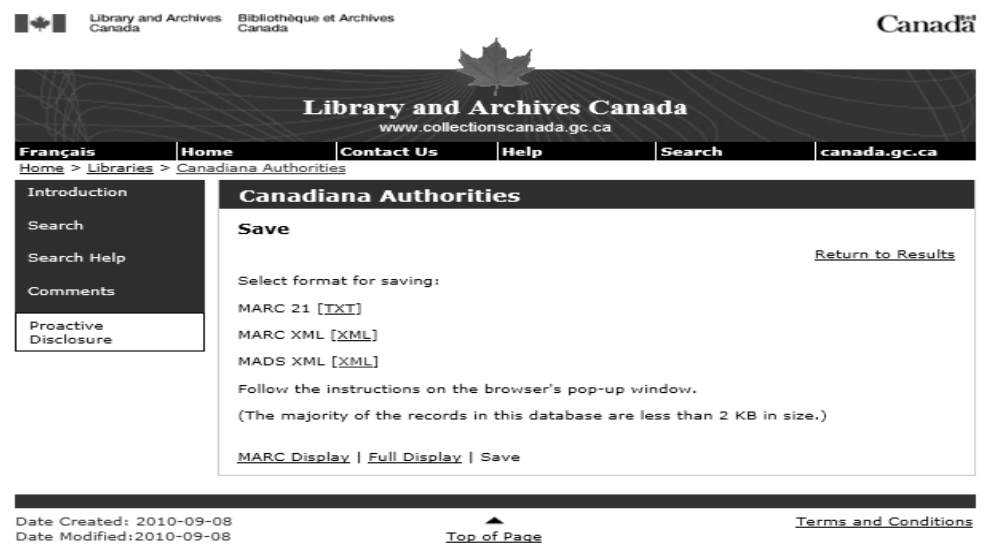

〈그림 4〉LAC 전거레코드 사례 2; Obama, Barack

\section{4. $\mathrm{MADS}$ 을 기반으로 한 전거데이터 상호운용성 분석}

디지털 자원의 증가와 웹 기술의 발전으로 인해 도서관 목록을 대하는 이용자의 기대는 높아져 가고 있다. 실제 윕에서 확인할 수 있는 도서관 정보는 목록을 중심으로 이루어지기 때 문에 도서관 목록은 이용자 수준에 맞는 인터 페이스 및 콘텐츠를 제공해야 한다. 즉 이용자 가 원하는 정보를 찾는 것 이상으로 이용자가 필요할 수 있는 정보를 제공하는 것이 중요하 다. 본 논문에서는 도서관이 이용자에게 전달 해야 할 잠재적인 목록 정보 중 전거데이터에 초점을 맞추고 있다.

21세기 도서관 전거데이터는 다음과 같은 의 미를 갖는다. 첫째, 서지레코드에 의존해서 전거 레코드를 작성하였던 기계가독목록을 벗어나 21 세기 목록에서는 '자원 기술을 모아둔 서지레코 드'와 '서지레코드 값이 될 수 있는 정보 집합인 전거데이터'라는 독립적인 관점에서 서지레코
드와 전거데이터 체제를 수용해야 한다. 둘째, 서지레코드 값인 전거데이터를 좀 더 정교하게 표현할 수 있는 제어시스템을 제공해야 한다. 이 를 위해 지식 체계와 같은 문헌정보학 관련 기준 들뿐만 아니라 웹 포털이나 다양한 학문 및 산업 분야에서 만들어낸 정보원을 활용할 필요가 있 다. 전거데이터의 확장성과 정확성이 보장된다 면 서지 기술과는 별도의 새로운 정보제공 툴을 개발할 수 있다. 셋째, 개체간의 관계를 중요하 게 다루어야 하며, 관계를 표현할 수 있는 정보를 함께 제공해야 한다. 서지 정보로 활용되는 개체 는 그 자체만을 가지고 이해되는 것이 아니라 다 른 개체들과의 관계 속에서 의미하는 바를 제시 해야 한다. 예컨대 지명 변천의 이유나 개인명, 단체명 이형간의 관계 등을 표현하는 게 중요하 다. 마지막은 앞에서 다룬 의미들을 종합적으로 정리하는 것으로, 상호운용성을 고려한 전거데 이터를 작성하는 것이다. 상호운용성은 타 시스 템의 전거데이터를 확보하는 것으로 자관의 전 거데이터에 대한 신속성, 신뢰성, 정확성, 확장 
성 등을 향상시킬 수 있다.

위에서 제시한 전거데이터의 새로운 의미는 서지레코드의 기능상의 요건(Functional Requirements for Bibliographic Records: FRBR), 전 거데이터의 기능상의 요건(Functional Requirements for Authority data: FRAD), 주제전거 데이터의 기능상의 요건(Functional Requirements for Subject Authority Data: FRSAD) 간의 관계에서도 표현되었다. 서지레코드와 그 레코 드의 값을 채우는 이름 전거데이터와 주제 전거 데이터를 연결한 것이다.

본 연구에서 다루고자 하는 MADS가 가지 고 있는 전거데이터로써의 특성들을 살펴보면 다음과 같다. 첫째, MADS는 '자원을 기술하는 체계'인 MODS와 연결되는 개념이지만 독립적 인 전거제어 프레임워크 즉 '자원을 표현하는 값 을 관리하고 확장하는 체계'이다. 둘째, MADS 에서는 이름 및 표제 전거(Name and Title Authority), 장르/형식 코드 및 용어(Genre/Form Code and Term), 주제표목 및 용어(Subject Heading and Term), 기관 코드(Organization Code), 관련자 및 역할 코드 및 용어(Relator and Role Code and Term), 직업관련 용어(Occupation Term) 등의 자원 코드(Source Codes) 들을 허
용하였다. 셋째, MADS는 표현하고자 하는 전 거 개체를 설명하고, 그와 관련된 개체들의 정 의 및 관계 정보를 포함하였다. 개체 간의 관계 는 MADS의 핵심 요소 중 연관 및 이형 요소 타 입에서 표현되었다. 기술 요소는 전거, 연관, 이형 요소인 핵심 요소 모두에 적용되지만 결합되는 핵 심 요소에 따라 그 기능이 결정된다. 전거 요소와 쓰이는 기술 요소는 단순히 대표 형식을 표현한 세부 정보라고 판단되는 반면에, 전거 요소와 연 결된 연관 및 이형 요소에 쓰이는 기술 요소는 연 관 및 이형 요소의 형태에 따라 그 역할이 구체 화되었다(〈그림 5〉 참조). 〈authority〉 요소의 〈name〉과 연결된 〈related〉, 〈variant〉 요소의 $\langle$ name〉는 〈related〉, 〈variant〉의 타입을 고려 하여 이해해야 한다. 예컨대 〈authority〉 요소의 〈name〉의 값 '연세대학교'와〈related〉 요소의 〈name〉의 값 '연희전문학교'는 〈related〉의 타입 'earlier'로 두 개체간의 관계가 이해될 수 있다.

마지막으로 MADS는 상호운용성이라는 측 면을 고려하여 XML 기반의 프레임워크로 개 발되었다.

4장은 3장에서 정리한 MADS 설계 원칙 및 레코드 구조를 바탕으로 전거데이터 상호운용성 을 위한 MADS 활용 방안을 모색하였다. MADS

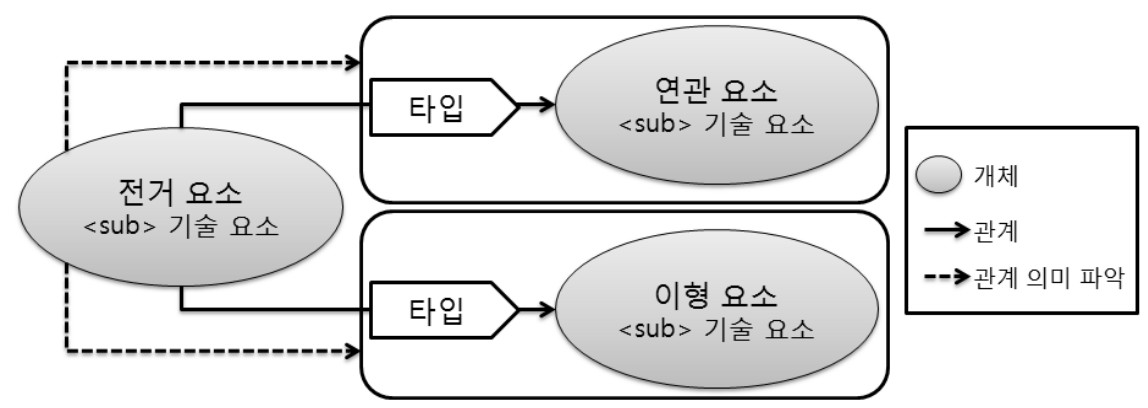

〈그림 5〉 핵심 요소간의 관계 표현 
는 인명뿐만 아니라 단체명, 장르, 주제, 시간, 공간 등의 전거를 다 포함하는 개념이다. 본 논 문에서는 인명을 중심으로 MADS의 활용 방안 을 정리하였으며, 국립중앙도서관, 한국과학기 술정보연구원(Korea Institute of Science and Technology Information: KISTI), 국사편찬위 원회의 한국역사인물시소러스 및 한국사데이터 베이스 전거데이터를 연계하고자 하였다.

국립중앙도서관과 KISTI는 인명 전거데이 터를 구축 중이기 때문에 본 논문과 관련된 실 험 데이터를 요청하여 확보하였고, 국사편찬 위원회의 인명 전거데이터는 웹 사이트에서 확 인하였다. 이중 국립중앙도서관 전거데이터만 이 KORMARC 형식이고, 그 외 KISTI와 국 사편찬위원회 전거데이터는 자관 메타데이터 를 XML 형식으로 표현한 것이다.

\section{1 정교한 전거데이터로 활용}

$\mathrm{MADS}$ 데이터는 전거 정보를 전달하기 위 해 다양한 요소들과 속성들을 정의하고 있다. 기계 중심의 부호화 형식인 MARC 전거레코 드와는 다르게 기술형식이 의미와 함께 전달될 수 있도록 요소와 속성을 선언하였다.

$\mathrm{MARC}$ 전거데이터는 인물 정보 제공을 위 해 대표적으로 $100,400,678 \$ \mathrm{a}$ (반복) 필드 등을 활용한다. MARC 전거 100 필드는 대표 형식을 지정하는 것으로 국가마다 기관마다 다 른 기준 및 표현 형식이 적용된다. MARC 전거 400 필드는 대표형식에 대한 이형들을 정리하고 있지만 대표형식과 이형간의 관계를 충분히 전 달하고 있지 않다. MARC 전거 678필드는 전 거 개체에 대한 요약 정보를 제공하는데, 실제
로는 역사적인 또는 전기적인 내용, 관심 분야, 흥미 분야, 역할, 소속 기관 등이 아무런 구별 없이 제공되고 있다. MADS는 서지레코드를 채우는 값을 제공할 뿐만 아니라 서지레코드에 서 그 값이 가지는 의미와 값들 간의 관계 그리 고 값의 형식을 통제할 수 있다.

〈그림 6〉은 MADS 스키마를 통해 Smith, John이라는 인물에 대한 이형들과 역사정보 주 기, 소속기관 등을 확인해 주고 있다. 전거제어 용 $\mathrm{MARC}$ 에서는 제한된 필드 안에서 의미를 중복적으로 사용하는데, 반면, 〈그림 6〉과 같이 MADS는 인물에 대한 다양한 정보를 구별하여 제공하고 있다. MADS로 표현된 전거데이터 는 의미 전달에 용이하며, 기존의 전거데이터 스키마에 비해 많은 정보를 제공하므로, 전거데 이터를 MADS로 표현하는 그 자체만으로도 의 의가 있겠다.

더 나아가, MADS 활용을 통해 전거데이터 관리에서 발생되는 동명이인 처리를 좀 더 신 속하고 정확하게 처리할 수 있겠다. 김미향은 동명이인이 많은 우리나라에서 동명이인의 식 별요소로 생몰년을 넣은 경우 또는 생년월일을 추가하는 경우에는 개인정보의 노출 우려가 있 다는 현장의 문제를 확인하였다. 또한 한자 표 기를 추가하여 동명이인 식별을 시도하였으나 이용자가 해당 저자의 한자 표기를 모르는 경 우에는 검색에 혼란과 어려움이 더 가중된다고 분석하였다(김미향 2009, 50).

〈그림 7〉은 KISTI 전거데이터 검색화면으 로 '김태수'라는 인명을 검색한 것이다. 〈그림 7>에 표시된 '김태수' 동명이인들 중 연세대학 교 문헌정보학과 교수였던 '김태수”를 식별하기 위한 방안은 다음과 같다. 


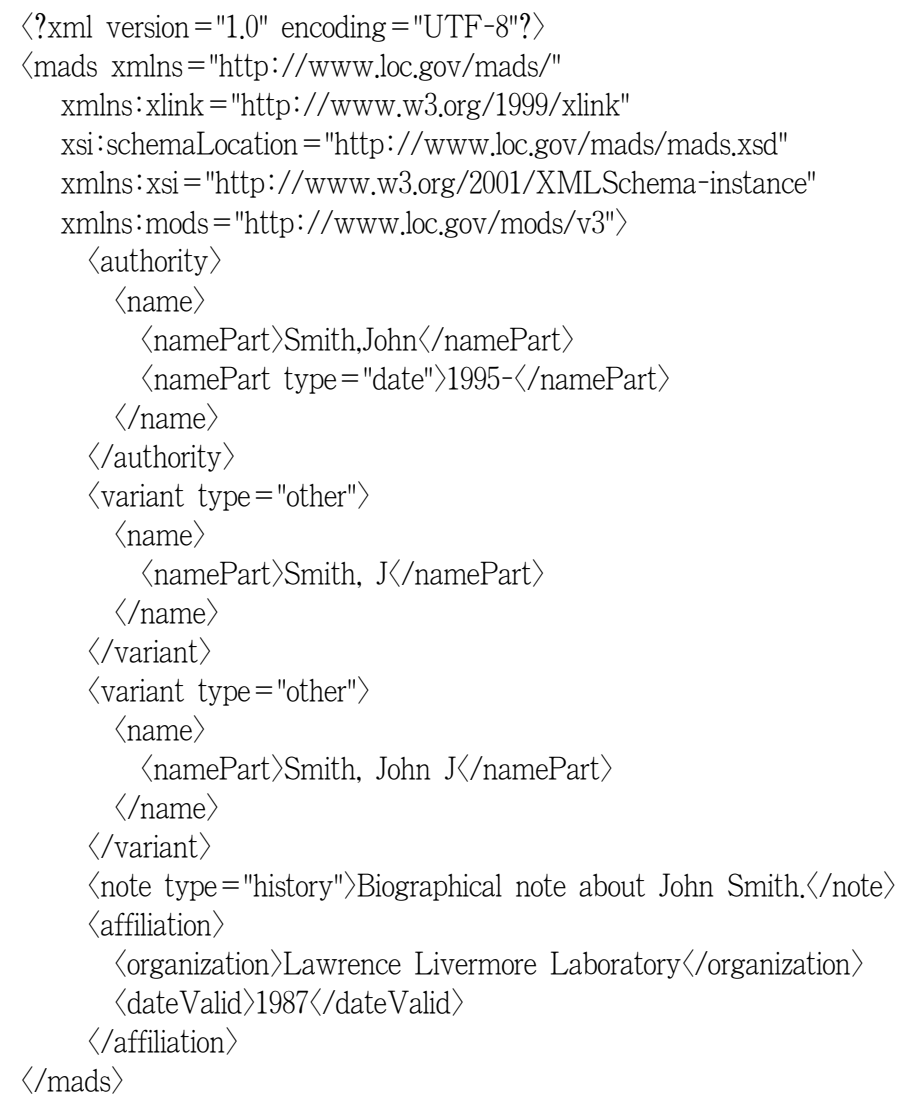

〈그림 6〉MADS 인명전거데이터 예시

* 출처: MADS 홈페이지(MADS Example Documents-Personal Name)

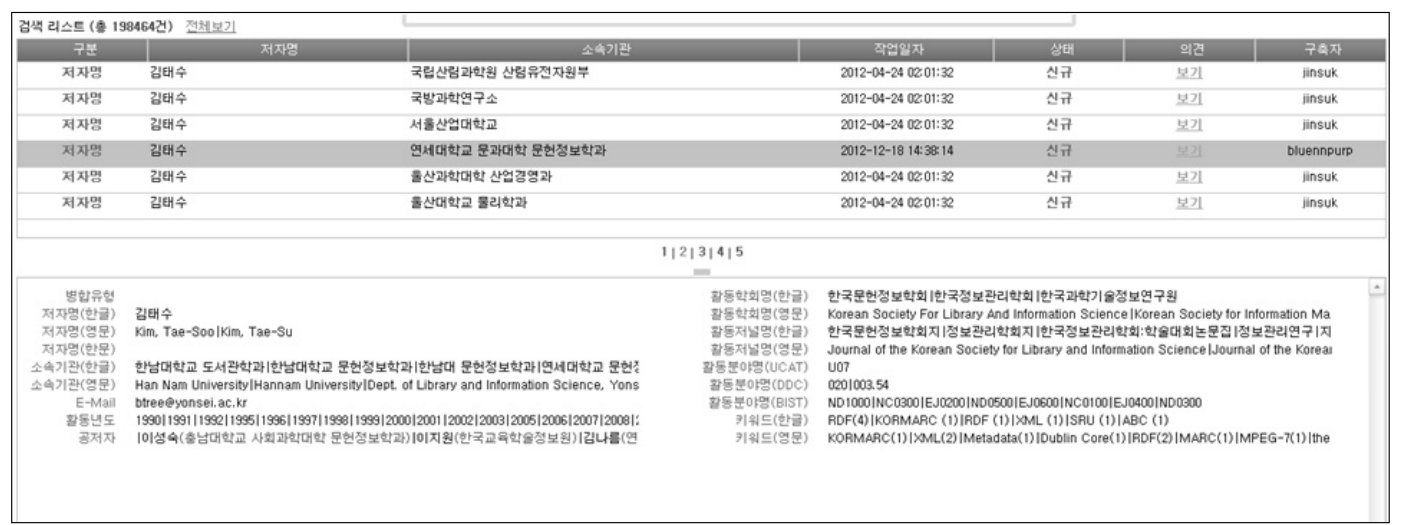




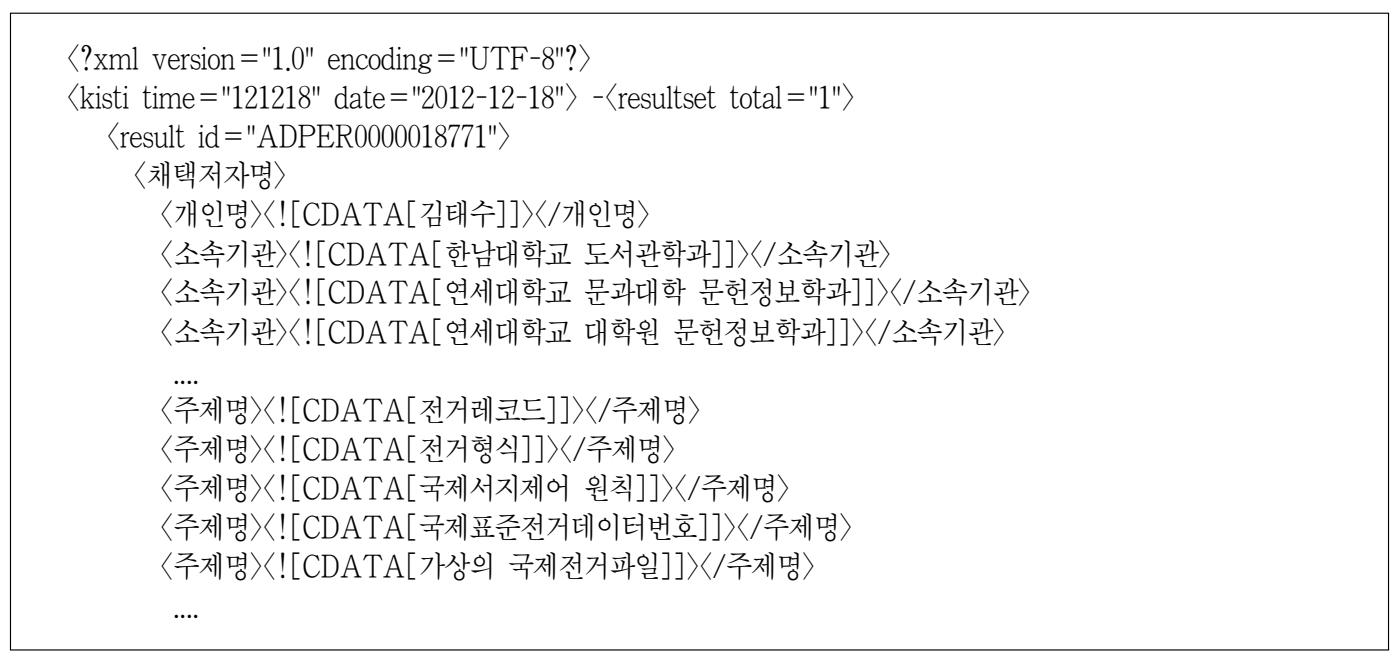

〈그림 8〉XML로 표현된 KISTI 전거데이터; 김태수

먼저, 〈그림 7〉에서 확인되는 연세대학교 문 헌정보학과 교수 ‘김태수’에 대한 전거데이터를 $\mathrm{KISTI}$ 에서 제공하는 XML 문서(〈그림 8〉 참 고)로 확인해야 한다.

그리고〈그림 8〉의 일부를 MADS로 표현해 야 한다.

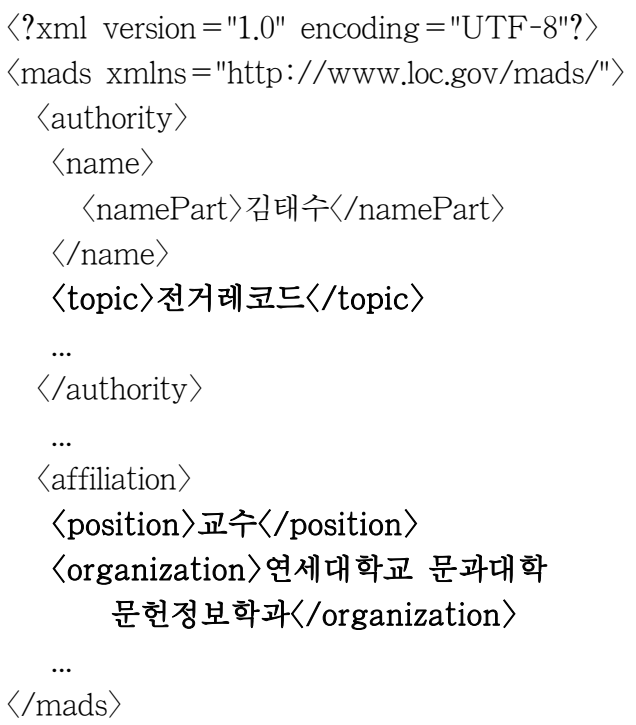

굵은 활자체로 표시된 전거데이터 - 소속기관 및 지위, 토픽-는 KISTI 시스템에서 동명이인 '김태수'에서 연세대학교 문헌정보학과 교수 '김 태수 만을 구별하는 중요한 정보로 사용될 수 있 다. 이러한 정보는 다른 스키마와의 연계시에도 유용하게 활용된다. 토픽과 같은 항목은 $\mathrm{FRAD}$ 에서 선언된 활동분야 요소〈fieldofActivity〉로 도 사용될 수 있다.

$\mathrm{MADS}$ 는 전거데이터 관리에서 발생되는 동 명이인 처리를 보다 신속하게 처리할 수 있다. 한국인명을 포함하여 명칭이라는 것은 중복적 으로 사용될 수밖에 없다. 동명이인 식별은 생 몰년, 식별자, 특정 저작의 저작, 소속기관 및 지위, 관련 홈페이지, 활동분야, 흥미분야 등의 부가정보원을 활용해야 하지만 단일 전거시스 템이 이와 같은 전거정보를 완벽하게 구축할 수는 없다. 더 나아가 이종의 전거데이터 스키 마들의 의미가 MADS라는 하나의 형식으로 표 현된다면 동명이인 식별을 유도할 수 있는 폭 넓은 정보를 확보하게 될 것이다. 


\section{2 이종의 전거데이터 활용}

〈그림 9〉는 국립중앙도서관 '한용운' 전거레 코드이고,〈그림 10〉은 '한용운'에 대한 국사편
찬위원회 한국역사인물시소러스 검색 화면이 다. 국립중앙도서관과 한국역사인물시소러스 와의 상호운용성을 위해 국립중앙도서관 레코 드의 일부 요소를 MADS로 표현하였다.

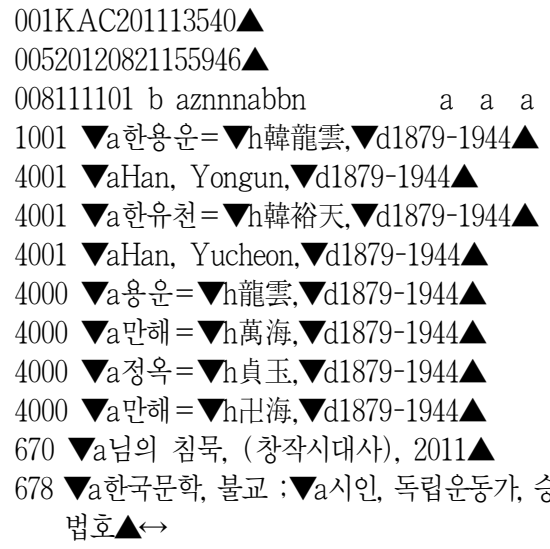

〈그림 9〉 국립중앙도서관 인명 전거데이터; 한용운

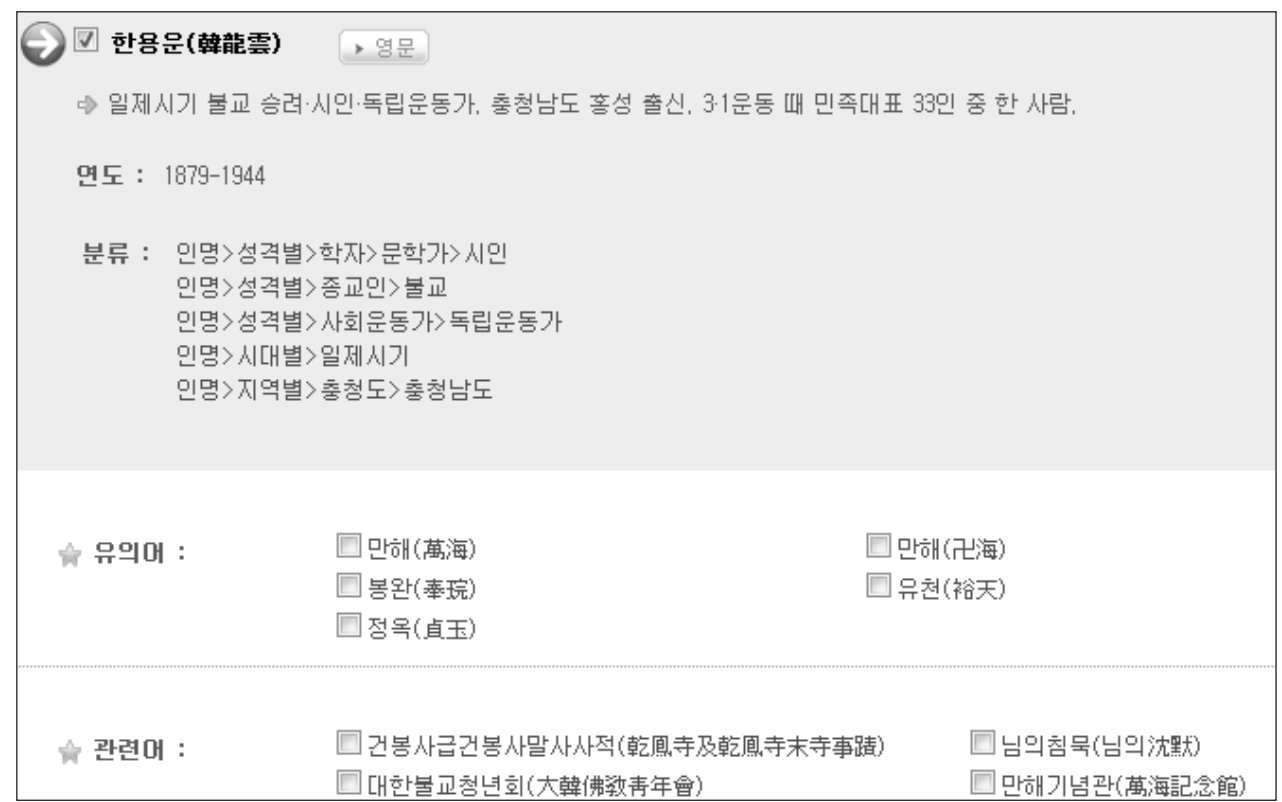

〈그림 10〉국사편찬위원회 한국역사인물시소러스; 한용운 


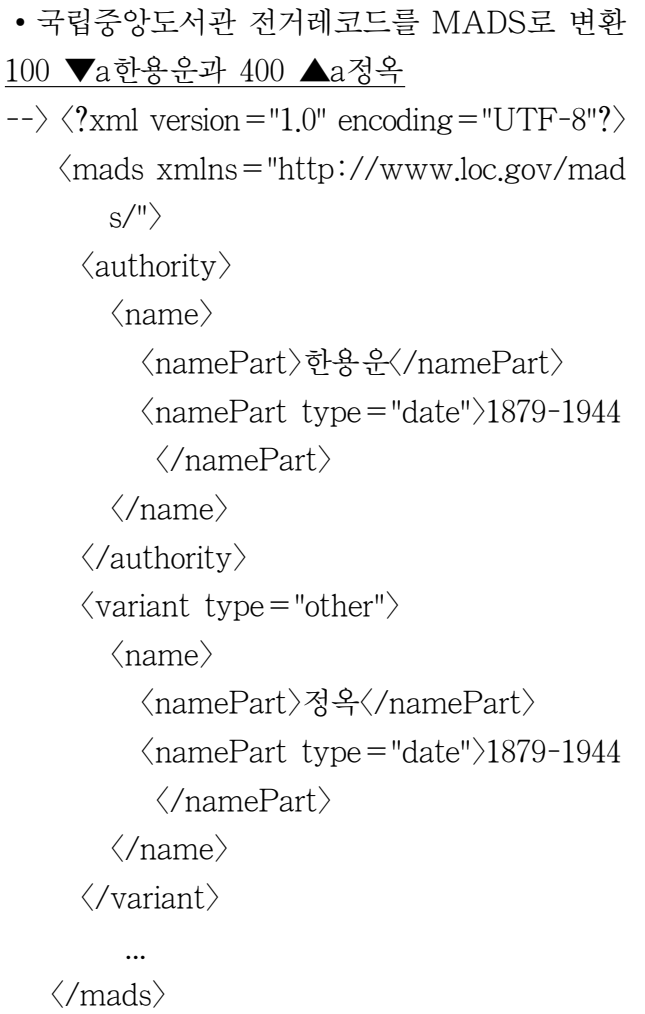

한국역사인물시소러스는 '한용운'과 유의어 와의 관계를 포함하고 있다. MADS의 확장성 을 고려하여 본 연구에서 임의로 이형 타입 속 성을 추가하여 한국역사인물시소러스에서 제공 하는 개체와 개체와의 관계를 구체화하였다.

국립중앙도서관과 한국역사인물시소러스와 의 상호운용성을 위해 한국역사인물시소러스의 일부를 MADS로 표현하였으며, 이형 타입 속성 을 확장하여 '본명'을 나타내는 'realName'을 선 언하였다.

- 한국역사인물시소러스를 MADS로 표현 '한용운'과 유의어 '정옥(貞玉)' $--\rangle\langle$ ? xml version $=" 1.0 "$ encoding $=" \mathrm{UTF}-8$ "? $\rangle$

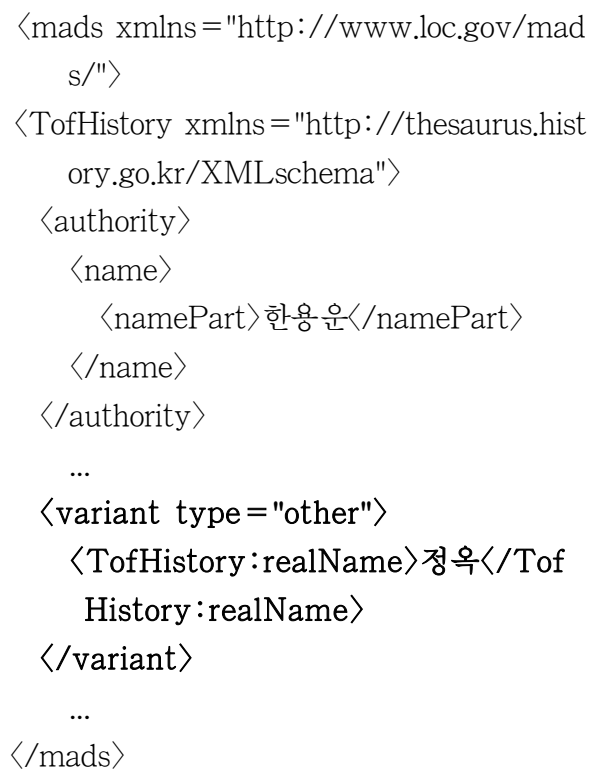

굵은 활자체로 표시된 한국역사인물시소러 스 데이터를 국립중앙도서관에 추가한다면 '한 용운'과 '정옥'의 관계가 '본명'이라는 이형의 표현임을 자동적으로 처리할 수 있겠다.

기존 MARC의 한계는 좀 더 풍부한 전거데이 터를 가지고 있는 이종의 전거 스키마와 MADS 를 통해 연계하는 것으로 해결될 수 있을 것이다.

\section{3 도서관 전거데이터와 타 분야 자료와의 연계가능성}

MADS 관련 문서들(MADS 2011, 2012b)에 서도 정리되었듯이, MADS는 XML을 기반으로 한 전거데이터 부호화 프레임워크이다. XML1) 의 'XML은 구조적인 데이터를 위한 것이다.'와 'XML은 RDF와 시맨틱 웹의 토대이다.'라는 기 본 개념은 XML이 MADS의 특성을 잘 발휘시

1) 출처. http://ko.wikipedia.org/wiki/XML 
킬 수 있음을 보여준다.

$\mathrm{MADS}$ 는 도서관, 정보과학 분야뿐만 아니라 박물관, 기록관, 다른 문화 기관에도 많은 영향을 줄 수 있는 MADS/RDF(Metadata Authority Description Schema in RDF)을 선언하였으며, 이는 한마디로 MADS를 RDF로 표현한 것이 다. MADS/RDF는 이름(개인, 단체, 지리 등), 시소러스, 택사노미, 주제명표목표 등을 사용하 기 위한 지식조직체계(knowledge organization system; KOS)이며, SKOS(Simple Knowledge Organization System) 와도 매우 관련이 있다. 단, SKOS에 비해 MADS의 활용범위가 더 넓 으며, $\mathrm{RDF}$ 로 표현된 MARC부터 링크드 데이 터 프로젝트(Linked Data Project: LDP)에 이르기까지 모두 적용될 수 있다. 그리고 문헌 정보학 분야와 그와 관련된 기술 시스템의 전거 데이터에 활용할 수 있도록 설계되었다(MADS 2012a).

$\mathrm{MADS} / \mathrm{RDF}$ 는 도서관뿐만 아니라 문화 · 예술 또는 기록과 관련된 전거데이터들 간의 연 계를 가능케 하였다. 전거데이터는 개체에 대 한 구조화되고 정리된 정보이다. 이러한 정보 에 대한 관심은 전통적으로 책이라는 개체와 연결된 도서관 환경에서 발달하게 되었다. 그 러므로 전거데이터에 대한 부분이 도서관 중심 으로 이해되는 것은 당연하나, 실제 전거데이 터는 도서관을 넘어서 인간이 존재하는 이 세 상 모든 것을 이해하는 것부터 시작해야 한다. 앞으로 도서관에 존재하는 정보는 박물관, 미 술관, 기록관뿐만 아니라 다양한 웹 자원들과 의 연계를 고민해야 한다. 이러한 고민은 무한 대의 정보를 취하는 웹이라는 콘테이너 안에서 도서관 전거데이터의 위력을 보여줄 수 있는 계
기가 될 수 있을 것이다.

\section{5. 결 론}

본 연구에서는 에이전트(사람, 조직), 사건, 용어(토픽, 장르, 지리 등)에 관한 전거데이터 $\mathrm{XML}$ 스키마인 MADS의 특성과 그 활용방안 을 확인하였다.

MADS 요소는 기본 요소(root elements), 핵 심 요소(main elements), 기술 요소(descriptor elements), 기타 요소(minor elements) 등으로 구성되어 있다. 기본 요소는 〈madsCollection〉 과〈mads〉 등으로 MADS 레코드들의 그룹은 MADS 컬렉션 요소인 〈madsCollection〉에 포 함되며, 개별 MADS 레코드는 〈mads〉 아래에 서 생성된다. 〈mads〉 아래 생성되는 요소는 핵 심 요소와 기타 요소이다. 핵심 요소는 전거 〈authority〉, 연관 〈related〉, 이형 〈variant〉 요 소 등으로 구성된다. 〈authority〉 요소는 필수 요 소이며, 하나 이상의 하위 요소를 가지고 있어야 한다. 하위 요소는 기술 요소(〈name〉, 〈titleInfo〉, $\langle$ topic〉, 〈temporal〉, 〈genre〉, 〈geographic〉, $\langle$ hierarchicalGeographic〉, 〈occupation〉) 가 되 며, 기술 요소는 〈authority〉뿐만 아니라〈related〉, 〈variant〉 요소 등 모든 핵심 요소의 하위 요소 가 된다(MADS 2012b).

$\mathrm{MADS}$ 는 MARC 형식을 계승함으로써 도 서관 목록규칙 중심으로 데이터 구조를 설계함 과 동시에 XML 구조를 활용하여 다양한 이종 의 메타데이터 기준들과의 공유 및 협력이 보장 된다는 장점을 가지고 있었다. 이를 확인하기 위 해 국립중앙도서관, KISTI, 국사편찬위원회의 
한국역사인물시소러스 및 한국사데이터베이스 전거데이터 일부를 활용하였다.

그 결과, 본 연구에서는 MADS을 기반으로 한 전거데이터 상호운용성을 다음과 같이 분석 하였다.

첫째, MADS로 표현된 전거데이터는 그 자 체가 정교한 전거데이터로 활용될 수 있다는 것 이다. MARC 전거데이터도 인물에 대한 자세한 부가 정보를 제공하기 위해 $100,400,678 \$ a$ (반복) 등의 대표 필드들을 활용하였다. MADS 로 표현된 전거데이터는 의미 전달이 용이하며, 기존의 전거데이터 스키마에 비해 많은 정보를 제공하고 있다. 이는 전거데이터를 MADS로 부호화하는 자체만으로도 의의가 있음을 보여 주는 것이다. 또한 전거데이터 관리에서 발생되 는 동명이인 처리를 보다 신속하게 처리할 수 있다. 한국인명을 포함하여 명칭이라는 것은 중 복적으로 사용될 수밖에 없다. 동명이인 식별은 생몰년, 식별자, 특정 저작의 저작, 소속기관 및 지위, 관련 홈페이지, 활동분야, 흥미분야 등의 부가정보원을 활용해야 하지만 하나의 전거데 이터가 이와 같은 정보를 완벽하게 구축할 수는 없다. 더 나아가 이종의 전거데이터 스키마들의 의미가 MADS라는 하나의 형식을 표현된다면 동명이인 식별을 유도할 수 있는 폭넓은 정보를 확보하게 된다.

둘째, 이종의 전거데이터를 활용할 수 있었 다. 기존 MARC의 한계는 좀 더 풍부한 전거 데이터를 가지고 있는 이종의 전거 스키마와 MADS를 통해 연계하는 것으로 해결될 수 있 을 것이다.

셋째, 도서관뿐만 아니라 문화 - 예술 또는 기
록과 관련된 전거데이터와의 연계도 가능하다. MADS에서 선언한 MADS/RDF는 도서관을 중심으로 다양한 서지기관과 문화 자원을 다루 는 기관, 웹 포털 등 디지털 전거데이터를 연동 시킬 수 있는 구조로 설계되었다.

$\mathrm{MADS}$ 를 기반으로 한 전거데이터 활용은 다음과 같은 의의를 가지고 있다. 첫 번째는 우 리나라 전거데이터 구축 현황에 부합되는 것으 로 다양한 전거데이터를 활용할 수 있다는 것 이다. 국립중앙도서관 연구 $(2009,52)$ 에 따르 면 전체 도서관의 $1 \%$ 에 해당하는 도서관만이 전거데이터를 구축하고 있는 상황이다. 이러한 우리나라 전거데이터 구축의 현황을 감안한다 면 외부의 데이터를 활용할 수 있는 방안을 고 려해 보아야 한다. 둘째, 도서관 목록은 대부분 $\mathrm{MARC}$ 을 기반으로 하고 있으므로, MARC 전 거를 수용할 수 있는 새로운 전거데이터 스키 마를 고려해야 한다는 것이다. 셋째, MADS의 풍부한 요소들을 활용할 수 있다는 것이다. 전 거제어의 관점에서 대표형식만을 고민하는 것 보다는 대표형식은 식별자와 같은 기능을 수행 하고 보다 다양한 전거 표현 및 개체 정보 등을 접근점으로 활용할 수 있는 스키마가 필요하다. 넷째, MADS은 XML을 기반으로 하고 있기 때문에 다양한 정보시스템과의 연계가 보장된 다는 것이다.

향후 실험을 통해 MADS를 기반으로 한 전 거데이터 상호운용성 평가가 필요하며, MODS 와의 연계도 보다 심층적으로 연구되어야 한다. 또한 MADS와 시맨틱 웹 기술 표준이나 온톨 로지와의 상호운용성도 연구되어야 할 것이다. 


\section{참 고 문 헌}

국립중앙도서관. 2009. 『차세대도서관을 위한 이름전거 및 온라인목록(OPAC) 연구』. 서울: 국립중앙도서관.

편. 2009.『전거레코드 표목의 구조 화 기준에 관한 연구』. 서울: 국립중앙 도서관.

국사편찬위원회 한국사데이터베이스. [online]. [cited 2012.10.25].

$\langle$ http://db.history.go.kr/〉.

국사편찬위원회 한국역사인물시소러스. [online].

[cited 2012.10.25].

$\langle$ http://thesaurus.history.go.kr/〉.

김미향. 2009.『기관 리포지터리의 검색기능 향

상을 위한 인명 접근점제어 시스템 구축 연구』. 박사학위논문. 연세대학교 대학 원, 문헌정보학과.

김태수. 1996. A Study on the development of the Korean subject headings. 『도서 관문화』, 37(5): 47-54.

2004. 전거제어활동의 최근동향 연구. 『지식처리연구』, 5(1/2): 1-32.

. 2008.『목록의 이해』. 서울: 한국도서 관협회.

김태수, 김이겸, 이혜원, 김용광, 박지영. 2009. 전거레코드 표목의 구조화 연구: 인명 과 단체명 전거레코드의 표목을 중심으 로. 『정보관리연구』, 40(3): 1-21.

이석형, 곽승진. 2010. 국내 학술논문 저자명 전 거데이터 구축 방안에 관한 연구. 『한국 비블리아학회지』, 21(1) : 105-118.
2012. 전거데이터 기반 학술논문 검색 시스템의 구축 및 평가에 관한 연구.『한 국문헌정보학회지』, 46(2): 133-156.

이혜원, 윤소영. 2011. 역사용어 온톨로지 모형 적용 방안 연구.『한국비블리아학회지』, 22(1) : 263-280.

Burger, Robert H. 1985. Authority work: the creation, use, maintenance, and evaluation of authority records and files. Littleton, Colo.: Libraries Unlimited. E-Matrix at the NCSU Libraries [online]. [cited 2012.10.20].

〈http://www.lib.ncsu.edu/e-matrix/ functionality.html $>$.

Gorman, Michael. 1982. Authority Control in the Prospective Catalog, In Authority Control: the Key to Tomorrow's Catalog, Proceedings of the 1979 Library and Information Technology Association Institutes. Edited by Mary W. Ghikas. Phoenix, Oryx Press, 166-185.

IFLA. 1999. Mandatory Data Elements for Internationally Shared Resource Authority Records. Report of the IFLA UBCIM Working Group on Minimal Level Authority Records and ISADN. [cited 2012.10.27]. 〈http://archive.ifla.org/VI/3/p19962/mlar.htm $\rangle$.

Library and Archives Canada; Canadiana 
Authorities [online]. [cited 2012.10.12]. $\langle$ http://www.collectionscanada.gc.ca /databases/canadiana-authorities/ind ex-e.html $>$.

MADS [online]. [cited 2012.10.1]. 〈http://www.loc.gov/standards/mads〉. MADS. 2011. MADS 2.0 - XML Format for Authorities Data. [cited 2012.10.1]. $\langle$ http://www.loc.gov/standards/mad s/mads-doc.html $>$.

MADS. 2012a. MADS/RDF Primer. [cited 2012.10.1].

$\langle$ http://www.loc.gov/standards/mad $\mathrm{s} / \mathrm{rdf} /\rangle$.

MADS. 2012b. Outline of Elements and Attributes in MADS 2.0. [cited 2012.10.1]. $\langle$ http://www.loc.gov/standards/mad $\mathrm{s} /$ mads-outline.html $\rangle$.

METS [online]. [cited 2012.10.2]. 〈http://www.loc.gov/standards/mets〉. MODS [online]. [cited 2012.10.1]. $\langle$ http://www.loc.gov/standards/mods〉.
MODS. 2009. Design Principles for Enhancements to MODS and MADS. [cited 2012.10.1]. 〈http://www.loc.gov/standards/mod s/design-principles-mods-mads.html $\rangle$. NACO [online]. [cited 2012.10.1]. $\langle$ http://www.loc.gov/aba/pcc/naco/〉. SKOS [online]. [cited 2012.10.2]. 〈http://www.w3.org/2004/02/skos/〉. Tillett, Barbara B. 2000. "Authority Control at the International Level." Library Resources \& Technical Services, 44(3): 168-172.

Tillett, Barbara B., Jaesun Lee, and Ana Lupe Cristán. 2007. IFLA cataloguing principles: steps towards an international cataloguing code, 4: report from the 4th IFLA Meeting of Experts on an International Cataloguing Code, Seoul, Korea. München: K.G. Saur.

VIAF [online]. [cited 2012.10.1]. $\langle$ http://viaf.org/〉. 